\title{
O ensino de Matemática na Base Nacional Comum Curricular nos anos finais do Ensino Fundamental
}

\author{
Renato Pinheiro da Costa ${ }^{1}$ \\ Camila Sousa ${ }^{2}$ \\ Leonardo Zenha Cordeiro ${ }^{3}$
}

\begin{abstract}
RESUMO
O presente trabalho que objetiva discutir o processo de implementação da Base Nacional Comum Curricular, as influencias das novas diretrizes para o processo de ensino e aprendizagem na instituição do ensino fundamental maior. O trabalho foi elaborado a partir do seguinte problema: Quais perspectivas e anseios em relação ao ensino de Matemática com a implementação da BNCC no ensino fundamental maior? Dessa forma, com base na metodologia qualitiva, com ênfase no estudo de caso, buscou-se analisar como se dá o ensino de Matematica nessa nova configuração, tomando como referencia o trabalho que vem sendo desenvolvido em uma escola na cidade de Altamira-Pa. A partir dos estudos em autores que discutem a temática, analisando as experiências da escola e da discussão sobre o objeto de estudo, implementação da BNCC, foi possível perceber a existem dúvidas e questionamentos por parte dos professores, o que nos leva a crer que há necessidade de formação e maior diálogo entre educadores e secretarias de educação no contexto da implementação da
\end{abstract} BNCC.

Palavras-Chave: Ensino de Matemática. Base Nacional Comum Curricular. Educação Básica.

The teaching of Mathematics in the Common Base National

\footnotetext{
${ }^{1}$ Doutor em Educação. Universidade Federal do Pará. Alatmia, Pará, Brasil. https://orcid.org/0000-0001-7132-0579. renatopc@ufpa.br.

${ }^{2}$ Especialista em Políticas Educacionais e Saberes Docentes. Prefeitura Municipal de Altamira. Alatmia, Pará, Brasil. https://orcid.org/0000-0002-6139-0984. kamilasousa19@gmail.com.

3 Doutor em Políticas Públicas e Formação Humana. Universidade Federal do Pará. Alatmia, Pará, Brasil. https://orcid.org/0000-0003-2474-8112.leozenha@gmail.com.
} 
Curriculum in the final years of Elementary Education

\begin{abstract}
This research work aims to discuss, through the process of implementation of the National Curriculum Base, the influences of the new guidelines for the teaching and learning process in middle school education. It was raised the question: What are the perspectives and aspirations regarding the teaching of mathematics with the implementation of BNCC in middle school? Thus, based on the qualitative methodology, with emphasis on the case study, we sought to analyze how mathematics teaching occurs in this new configuration, taking as a reference the work that has been developed in a school in the city of Altamira-Pa. From theoretical background, analyzing the school experiences the discussion on the object of study, implementation of the $\mathrm{BNCC}$, it was possible to realize that there are doubts and questions on the part of the teachers, it was possible to understand that there are doubts and questions from teachers, which leads us to the need for training and intensive dialogue between educators and education departments in the context of the implementation of the BNCC.
\end{abstract}

KEYWORDS: Math teaching. National Curriculum Base. Middle school.

\title{
La enseñanza de la Matemática en el Currículo Nacional de Base \\ Común en los últimos años de Educación Primaria
}

\section{RESUMEN}

El presente trabajo objetivo discutir a través del proceso de implementación de la Base National Curriculum las influencias de las nuevas pautas para el proceso de enseñanza y aprendizaje en la institución de Educación primaria. El trabajo se elaboró a partir del siguiente problema: ¿Qué perspectivas y ansiedades con respecto a la enseñanza de la Matemática con la implementación de BNCC en la educación primaria? Por lo tanto, con base en la metodología cualitativa, con énfasis en el estudio de caso, buscamos analizar cómo se lleva a cabo la enseñanza de las Matemáticas en esta nueva configuración, tomando como referencia el trabajo desarrollado en una escuela en la ciudad de Altamira-Pa. A partir de los estudios de los autores que discuten el tema, analizan las 
experiencias de la escuela y la discusión sobre el objeto de estudio, la implementación del BNCC, fue posible comprender cómo existen dudas y preguntas de los docentes, lo que nos lleva a la necesidad de capacitación y un mayor diálogo entre educadores y departamentos de educación en el contexto de la implementación del BNCC

Palabras clave: Enseñanza de la Matemática. Base de Currículum Nacional Común. Educación básica.

\section{Introdução}

A discussão do ensino da Matemática no campo acadêmico traz muitos desafios para a educação, ganhando destaque quando o assunto é a necessidade de mudança do modelo que tem como referência as orientações dos Parametros Curriculares Nacionais (PCNs), somada a falta de recursos didáticos e formação continuada de professores para apropriação de metodologias que favoreçam o processo educacional. Desse modo a disciplina se torna de difícil compreensão, não tendo muita relação com a realidade social do aluno, como afirma Catarina Maria Vitti (1999, p.19):

O fracasso do ensino de Matemática e as dificuldades que os alunos apresentam em relação a essa disciplina não é um fato novo, pois vários educadores já elencaram elementos que contribuem para que o ensino da Matemática seja assinalado mais por fracassos do que por sucessos.

No cenário atual, em que a Matemática, assim como a maioria das disciplinas do ensino fundamental, são ministradas com resquícios do método tradicionalista, indagamos se as atuais diretrizes curriculares dessa etapa de ensino seriam suficientes para possibilitar ao processo educacional caminhar para uma abordagem mais eficaz, que pudesse possibilitar aos alunos acesso ao conhecimento necessário do ensino de Matemática e condiza a sua 
realidade sócio cultural.

Dessa forma foi verificado que a articulação de um currículo escolar que correspondesse às necessidades de aprendizagem dos alunos é uma concepção que há muito vem sendo discutida no âmbito do sistema de educação. Nesse sentido averiguamos também que ao longo dos anos desde a implementação da Lei de Diretrizes e Bases da Educação (LDB) 9.394/96, vêm sendo cogitada uma estrutura curricular que pudesse uniformizar o currículo para que as diferenças de conhecimento pudessem ser superadas. Dessa forma é que uma noção de base comum do currículo, que já vinha sido pensada há muito tempo, foi instituída e em 2017, ocorreu a aprovação do documento colocando em discussão o papel do Estado na elaboração, implementação e regulação de uma proposta para nortear o ensino da educação básica.

A Base Nacional Comum Curricular (BNCC) é um documento de caráter normativo que define o conjunto orgânico e progressivo de aprendizagens essenciais que todos os alunos devem desenvolver ao longo das etapas e modalidades da Educação Básica, de modo a que tenham assegurados seus direitos de aprendizagem e desenvolvimento, em conformidade com o que preceitua o Plano Nacional de Educação (PNE) (BRASIL 2017, p. 7).

A partir da homologação da BNCC no dia 06 de março, em uma escola da rede pública de ensino do município de Altamira-Pa foi realizado um evento denominado "O dia da BNCC". Na ocasião professores da etapa do ensino fundamental maior e gestores fizeram leituras e discussões sobre o documento a fim de estudar, conhecer e discutir a BNCC. Diante disso, procurei fazer análise sobre como ficaria o trabalho do professor e o ensino de disciplinas com a Matemática, mediante as mudanças proposta para a educação básica. Para o nível fundamental maior ${ }^{4}$.

\footnotetext{
${ }^{4} 6^{\circ}$ ao $9^{\circ}$ ano do Ensino Fundamental.
} 
Por entender que essa é política norteadora que terá grande impacto em toda a estrutura curricular da educação básica, averiguei que os impactos da BNCC precisam ser bem analisados, e essa reflexão deve começar pela instituição escolar para que possamos ter elementos para dizer se as mudanças implementadas estão sendo ideais para a formação de competências e habilidades dos alunos na etapa fundamental da educação básica.

Desse modo, este estudo foi construído objetivando discutir o processo de implementação da Base Nacional Comum Curricular, as influencias das novas diretrizes para o processo de ensino e aprendizagem na instituição do ensino fundamental maior. Sendo que o professor de Matemática desenvolve um trabalho didático pedagógico que compreende o ensino de raciocínios lógicos com a utilização de metodologias, fundamentado em teorias e parâmetros norteadores da prática docente, refletimos se durnate a implementação da BNCC na rede municipal de educação as práticas pedagógicas já acumuladas na experiência da sala de auala serão consideradas?

A fim de atender o objetivado, esta pesquisa foi desenvolvida com base no seguinte problema: Quais perspectivas e anseios em relação ao ensino de Matemática com a implementação da BNCC no ensino fundamental maior? E para melhor demonstrar a apropriação da reorientação curricular que a BNCC traz, tomo como referência as mudanças direcionadas à disciplina Matemática do $6^{\circ}$ ao $9^{\circ}$ ano, para detalhar como o professor está adaptando o currículo dessa área de conhecimento mediante a compreensão e orientação pedagógica da rede municipal de ensino de Altamira.

Por ser uma investigação que toma como base para sua produção as reações desencadeadas na instituição escolar a partir das discussões e impressões sobre o trabalho do professor, o desenvolvimento curricular com relação à implementação da BNCC, que poderá implicar na alteração da sequência didática e da rotina curricular dos professores, esta pesquisa será pautada no método de pesquisa qualitativa com enfoque no estudo de caso. 
De acordo com Marconi e Lakatos (2011, p. 269) a pesquisa qualitativa "preocupa-se em analisar e interpretar aspectos mais profundos, descrevendo a complexidade do comportamento humano". E neste caso, pautada nessa metodologia, tivemos maior possibilidade de lançar mão das manifestações da comunidade escolar ocorrida durante o período de estudo sobre a BNCC para o ensino de Matemática nos anos finais do Ensino Fundamemtal. E desse modo, fazendo o estudo de caso foquei especificamente nas ações ocorridas na instituição em torno das formações para a implementação da BNCC.

Com este estudo tive por objetivo participar das discussões sobre BNCC, em especifico na área da Matemática e principalmente contribuir com a comunidade da Escola Municipal Sebastião de Oliveira compreendendo qual o sentido dessa reorganização curricular e quais possíveis impactos ela traz para a formação dos alunos, ressaltando que o processo de implementação deverá ocorrer até o início do ano de 2020.

\section{O ensino de Matemática no ambiente escolar}

O ensino de Matemática nas instituições de ensino é um procedimento que no sistema de ensino passa pela organização de um currículo que contemple diversas atividades, como cálculo, operacionalização, resolução de problemas e tantas outras atividades lógicas que envolvem esse aprendizado.

$\mathrm{Na}$ sociedade moderna, devido estamos em constante atividades que envolvem essas operações Matemática como calcular, contar, equacionar, parecem ser algo comum e que não necessita de conhecimentos aprofundados para tais ações. Entretanto, essa é uma concepção equivocada se desenvolveu por não entendermos o que significa educação e como diferenciar os espaços em que sua manifestação ocorre.

Sendo que na LDB 9.394/96 educação é um procedimento que envolve amplo processo formativo, também podermos inferir que o ensino de Matemática também passa por esses mesmos preceitos, com é possível verificar em Brasil (2017, p.8). 
Art. 1 A educação abrange os processos formativos que se desenvolvem na vida familiar, na convivência humana, no trabalho, nas instituições de ensino e pesquisa, nos movimentos sociais e organizações da sociedade civil e nas manifestações culturais.

$\S 1$ Esta Lei disciplina a educação escolar, que se desenvolve, predominantemente, por meio do ensino, em instituições próprias. $\S 2$ A educação escolar deverá vincular-se ao mundo do trabalho e à prática social.

A legislação educacional, ao mesmo tempo que conceitua educação nos esclarece que sua função é normatizar o ensino desenvolvido nas instituições escolares, por isso, é necessário a constituição de um sistema de ensino que oriente como essa formação ocorrerá nos estabelecimentos escolares, para que desse modo possamos estar ofertando um ensino de qualidade, que permita que o aluno ter acesso à formação, proporcionando qualificação profissional e consequentemente participação social.

Como princípio dessa normatização dos procedimentos educacionais direcionados pelo sistema de ensino, temos as concepções de educação orientadas pelos Parâmetros Curriculares Nacionais - PCNs, em (Brasil, 1998), que determina o ingresso no meio escolar deve ser proporcionados ao aluno situações em que favoreçam o desenvolvimento da capacidade de posicionar-se de maneira crítica, tomar decisões coletivas, percebe-se como ser integrante, agente transformador do ambiente em que se encontra saber utilizar diferentes linguagens, expressar e comunicar ideias, utilizar raciocínio logico para solucionar problemas.

Muito embora a formação não ocorra somente no ambiente escolar, no atual panorama educacional regido pelo sistema de ensino, o processo formativo e de aprendizagem organizado por um currículo que prepare o aluno para a cidadania deve ser desenvolvido levando em consideração parâmetros formais, e este só pode ser realizado na instituição de ensino, lugar onde deve ocorrer troca e experiências, na relação dicotômica entre 
educador e educando.

A relação desenvolvida no ambiente escolar é parte do processo formativo que, por conseguinte, é uma pratica educativa baseada no diálogo que traz resultados satisfatórios ao processo de ensino e aprendizagem como diz Paulo Freire.

[...], o diálogo é uma exigência existencial. E, se ele é o encontro em que se solidarizam o refletir e o agir de seus sujeitos endereçados ao mundo a ser transformado e humanizado, não pode reduzir-se a um ato de depositar ideais de um sujeito no outro, nem tampouco tornar-se simples troca de ideias a serem consumidas pelos permutantes. (FREIRE, 2005, p. 91).

Para que este processo se dê de maneira satisfatório é necessário ter por base o respeito e o ideal de igualdade. Como se posiciona D' Ambrósio (1991), ao ingressar no ambiente escolar, o conhecimento prévios alunos na maioria às vezes é desprezado, ando ênfase apenas ao currículo estabelecido para o ano letivo. No que diz a respeito aos conteúdos, muitas vezes parece não ter sentido aos alunos, pois a linguagem utilizada demostra-se distante da compreensão de todos.

É preciso conhecer como ocorre o desenvolvimento à compreensão dos alunos, em relação à temas e áreas de conhecimento, como por exemplo a gramática, geografia, história, Matemática, e assim por diante, considerando a diversidade cultural de cada aluno.

No caso em específico da disciplina Matemática, D’ Ambrósio (1991), aprecia que a Matemática é a disciplina que na maioria apresenta carga horaria maior em relação às demais disciplinas, isso se deve a fator que essa se mostra uma ferramenta competente para desenvolver a capacidade de lidar com situações reais de forma diferenciada, por apresentar essa relevância a disciplina é vista como uma área de difícil compreensão, contribuindo assim 
para um alto índice de evasão escola e reprovação.

Ao perceberem a Matemática como algo difícil e não se acreditando capaz de aprendê-la, os estudantes, muitas vezes, desenvolvem crenças aversivas em relação à situação de aprendizagem, o que dificulta a compreensão do conteúdo e termina por reforçar sua postura inicial, gerando um círculo vicioso (FERREIRA, 1998, p. 20).

Pelo apanhado do autor, o grau de complexidade de uma determinada área de conhecimento, no caso a Matemática, acaba por produzir determinadas resistências dos estudantes em se aprofundarem ou se esforçarem para conhecer melhor o assunto estudado. E por vezes, a recusa em quer se dedicar a tal estudo, produz o desânimo nos professores que são levados à ensinar o básico, não garantindo o nível de conhecimento necessário aos estudantes.

Segundo os PCNs que orientam o ensino de Matemática:

Muitos têm a sensação de que a Matemática é uma matéria difícil e que seu estudo, se resume a decorar uma serie de faros matemáticos sem compreende-los e sem perceber suas aplicações e que isso lhes será de pouca utilidade. Tal constatação nos leva a assumir o desinteresse, na falta e empenho e mesmo na preocupação diante dos resultados insatisfatórios ou no sentimento de insegurança, bloqueio e até uma certa convicção de que são incompetentes para aprende-la, o que leva a se afastar da Matemática em situação futura (Brasil, p. 79).

Nos PCNs são apontados indícios de que o ensino de Matemática é um processo complexo, e que são encontradas resistências da parte dos alunos. Neste caso, o que pode explicar esse desinteresse pela Matemática é fato de que por vezes a disciplina é ensinada com excessivas preocupações na 
utilização da linguagem formal e resolução de exercícios, levando-os a questionarem sua aplicação no cotidiano.

Pelo amplo entendimento de educação, e como ela ocorre dentro das instituições escolares, vale apena ressaltar que o currículo escolar precisa estar em constante revisão. Não para desconstruir o que já está instituído como temas a serem estudados nas instituições de ensino, mas para que o sistema de ensino revise os investimentos que estão sendo feitos para melhorar a qualidade da educação desenvolvida, pois, devido a forma mecânica como o currículo se apresente, disciplinas como a Matemática não se são suficientemente aproveitadas pelos estudantes. Por isso, deve haver mais investimento na formação de professores, mais aquisição de recursos didáticos, maior ênfase na elaboração de projetos de incentivo ao estudo, em melhorias na infraestrutura das instituições escolares.

Consideramos que o ensino da Matemática deve-se adequar aos novos paradigmas da educação, que propõe uma educação dando ênfase a cidadania e ao social, que os alunos sejam capazes de refletir a respeito dos problemas apresentados pela sociedade, desenvolvendo competências e habilidades que os tornem cidadãos críticos frente a todas essas transformações que estão ocorrendo na atualidade.

\section{O Ensino de Matemática na Base Nacional Comum Curricular}

Embora a BNCC seja um projeto que ainda está em tramitação no âmbito municipal devido estar em fase de implementação, o sistema de ensino local está tentando promover sua efetivação, entretanto, há de se notar que cada unidade de ensino tem uma forma de conduzir o processo de elaboração da proposta curricular. E neste caso, durante a convergência do paradigma norteado pelos PCNs para BNCC, essa experiência que considera a prática do professor e a relação do currículo com a realidade social do aluno, precisa ser valorizada.

O currículo escolar apresenta inúmeras complexidades devido ele 
buscar atender as demandas da sociedade, visando o preparo para a cidadania, para o trabalho e para introduzir o alunado no campo da ciência e tecnologia. Dessa forma, constantemente o sistema de ensino promove mudanças na estrutura educacional, buscando aproximar a formação as exigências do sistema social.

Desde a década de 1990, com a promulgação da LDB 9.394/96, já vinha sendo sinalizado a implementação de uma base nacional comum curricular. Entretanto, somente a partir de 2015 é que começou a ser produzido um movimento em vista de atender essa diretriz legal. A saber, a Base Comum Curricular Nacional - BNCC, é um documento que visa nortear o que é ensinado nas escolas públicas brasileiras, abrangendo todos os níveis da educação básica, de maneira que os direitos dos alunos sejam garantidos. (BRASIL,2017).

[...] Em conformidade com o que preceitua o Plano Nacional de Educação (PNE). Este documento normativo aplica-se exclusivamente à educação escolar, tal como a define o $§ 1^{\circ}$ do Artigo $1^{\circ}$ da Lei de Diretrizes e Bases da Educação Nacional (LDB, Lei $n^{\circ}$ 9.394/1996)1, e está orientado pelos princípios éticos, políticos e estéticos que visam à formação humana integral e à construção de uma sociedade justa, democrática e inclusiva, como fundamentado nas Diretrizes Curriculares Nacionais da Educação Básica (DCN). (BRASIL, 2017, p.7).

Como documento, a BNCC ela regulamenta o currículo escolar nacional, e de acordo com Pinto (2017, p.1045), a BNCC é uma forma que o estado encontra para engessar o processo educacional, posto, sua proposição estar ocorrendo em uma conjuntura desfavorável para a promoção de práticas democráticas, e formação cidadã humanista, voltada mais para os interesses do mercado, do que o desenvolvimento das habilidades e capacidades humanas.

A primeira versão da BNCC foi colocada para discussão em junho de 
2015, na data citada ocorreu o I Seminário Interinstitucional para sua elaboração, no presente momento reuniu-se especialistas da área da educação. A Portaria n.592, de junho de 2015 instituiu a Comissão de Especialistas para a elaboração de propostas para a BNCC.

Art. $1^{\circ}$ - Fica instituída a Comissão de Especialistas para a Elaboração da Proposta da Base Nacional Comum Curricular. $\S 1^{\circ}$ - A Comissão de Especialistas será composta por 116 membros, indicados entre professores pesquisadores de universidades com reconhecida contribuição para a educação básica e formação de professores, professores em exercício nas redes estaduais, do Distrito Federal e redes municipais, bem como especialistas que tenham vínculo com as secretarias estaduais das unidades da Federação. (BRASIL, 2015)

Em junho do mesmo ano foi lançado o Portal da Base, que apresentava ao público o processo de elaboração do documento e estabelecia a participação da sociedade, com sugestões através do portal. Em setembro o MEC lançou a $1^{\mathrm{a}}$ versão da BNCC, aberta a consulta pública, havendo cerca de 12,2 milhões de diversas contribuições de educadores e instituições.

No campo da Matemática que é do que se trata a pesquisa em questão analisaremos as mudanças propostas pela BNCC, confrontando diferenças e semelhanças aos Parâmetros Curriculares Nacionais no que diz respeito ao ensino e aprendizagem da disciplina. Apesar das alterações a BNCC não propõe uma ruptura com a visão adotada pelos PCNs.

A Matemática é uma área do conhecimento que se apresenta muitas vezes de forma complexa, no entanto se mostrada de forma contextualizada e interdisciplinar, se mostra um campo fascinante que deve estar ao alcance de todos e sua democratização deve ser meta prioritária dos professores (BRASIL, 1997).

A Base Nacional Comum Curricular para o ensino da Matemática visa definir aprendizagens progressivas e essências para todos os alunos da 
educação básica, dialogando sempre com a LDB e com o Plano Nacional de Educação.

[...] cabe à União estabelecer, em colaboração com os Estados, o Distrito Federal e os Municípios, competências e diretrizes para a Educação Infantil, o Ensino Fundamental e o Ensino Médio, que nortearão os currículos e seus conteúdos mínimos, de modo a assegurar formação básica comum (BRASIL, 1996).

Pelo disposto na proposta da BNCC, o ensino deve-se adequar aos novos paradigmas da educação, que propõe uma educação dando ênfase a cidadania e ao social e que os alunos sejam capazes de refletir a respeito dos problemas apresentados pela sociedade, desenvolvendo competências e habilidades que os tornem cidadãos críticos frente a todas essas transformações que estão ocorrendo na atualidade.

As mudanças propostas pela BNCC na área da Matemática têm por objetivo mudar a maneira como a Matemática é ensinada, sem tantas fórmulas e memorizações, abrindo espaço para mais reflexão e interpretação, uma das mudanças importante foi a progressão para favorecer aprendizagem, ou seja, há preocupação que a progresso seja feito da forma mais natural possível, dos conceitos mais simples ao mais complexos, levando em consideração as habilidades desenvolvidas pelo aluno.

Pela lógica da proposta curricular é inevitável a reorganização dos conteúdos para o ensino de Matemática, a saber, o que antes era ensinado de forma isolada, na BNCC são conhecimentos que precisam estar interligados acompanhando a teoria detalhada em Rabelo (2000), como por exemplo a álgebra que nos PCNs só eram propostos nos anos finais do segmento que na nova composição da disciplina irá compor o conteúdo desde o início do ciclo de aprendizagem. Desse modo, o aluno será instigado a pesquisar, investigar, coletar dados e organizar, vivenciando de maneira efetiva a pesquisa, que é essencial na sua formação já que todos os dias se depara com dados 
estatísticos nas diferentes mídias.

A composição de um currículo com conhecimentos interligados é uma tendência que no campo eduacional vem sendo prestigiada haja vista os órgãos que organizam a educação do país entenderem que essa é uma metodologia que favorece a articulação entre conhecimentos escolares e conhecimento de mundo como é explicitado em Brasil (2017,p.272):

Propõe a abordagem de conceitos, fatos e procedimentos presentes em muitas situações-problema da vida cotidiana, das ciências e da tecnologia. Assim, todos os cidadãos precisam desenvolver habilidades para coletar, organizar, representar, interpretar e analisar dados em uma variedade de contextos, de maneira a fazer julgamentos bem fundamentados e tomar as decisões adequadas. Isso inclui raciocinar e utilizar conceitos, representações e índices estatísticos para descrever, explicar e predizer fenômenos. (BRASIL, 2017, p. 272)

A abordagem educacional em vista do desenvolvimento das habilidade que a BNCC busca promover passa por procedimentos que repercutirão diretamente na atividade pedagógica do professor, uma vez que conceitos como letramento matemático passa a ser requisitado como parte do componente curricular, o que pode ser um desafio aos educadores e alunos, pois traz necessidade de mudança de postura do educador que geralmente o aluno espera que a Matemática não tenha leitura e que as respostas sejam rápidas.

O Ensino Fundamental deve ter compromisso com o desenvolvimento do letramento matemático, definido como as competências e habilidades de raciocinar, representar, comunicar e argumentar matematicamente, de modo a favorecer o estabelecimento de fruição). Conjecturas, a formulação e a resolução de problemas em uma variedade de contextos, utilizando 
conceitos, procedimentos, fatos e ferramentas Matemáticas. É também o letramento matemático que assegura aos alunos reconhecer que os conhecimentos matemáticos são fundamentais para a compreensão e a atuação no mundo e perceber o caráter de jogo intelectual da Matemática, como aspecto que favorece o desenvolvimento do raciocínio lógico e crítico, estimula a investigação e pode ser prazeroso. (BRASIL, 2017, p. 264).

No tema de Matemática financeira, ganhou destaque e um enfoque diferenciado, agora o objetivo é formar cidadãos que saibam tomar decisões que envolva economia tanto no âmbito pessoal mais especifico como no geral, agora se usa o termo Educação Financeira, cabendo ao professor promover o aprendizado necessário. Não esquecendo as mudanças no campo da tecnologia a serviço da aprendizagem, o documento deixa bem claro o como essa área é de extrema importância, havendo o reconhecimento no texto de que as tecnologias digitais não são separadas da Matemática.

Tendo em vista que a escola visa preparar indivíduos para viver em sociedade, devendo se adequar as propostas apresentas pela BNCC, construindo seu currículo usando como orientação o documento.

\section{O ensino de Matemática na escola e os possíveis impactos da BNCC nesse processo}

O ensino escolar faz parte de uma organização que tem sua base no sistema nacional de ensino, por isso, ela ganha o status de educação formal, por conter aspectos de um ensino que garante uma formação pautada em procedimentos que visam o desenvolvimento de habilidades e competências dos alunos. Nesse sentido, o ensino das disciplinas segue um rito fundamentado em orientações institucionais como os PCNs que norteiam o trabalho do professor para o desenvolvimento adequado do currículo.

Nas escolas, as orientações oriundas dos PCNs são apuradas e pela ação pedagógica do corpo técnico e dos professores é adaptada a realidade dos 
alunos a fim de atender as peculiaridades sociais e culturais deles. Desse modo, o professor procura preparar o plano de curso e os planos de aula levando em consideração as características peculiares dos alunos de cada turma.

Nesse sentido, tomando como exemplo a rotina pedagógica de uma escola da rede muncipal de Altamira, cidade localizada na região sudoeste do Estado do Pará, a organização das aulas das disciplina segue um rito metodológico que envolve a equie gestora, coordenação pedagógica e professores na preparação das temáticas dentro de uma sequencia didática estruturada para o período de duas semans, ou dez aulas, como explicitado no Quadro 1.

No caso expecífico da disciplina Matemática tem se tido o cuidado com o atendimento para o desenvolvimento das habilidades dos alunos, o que pode ser verificada na sequencia didática Quadro 1, elaborado pelo professor da disciplina tomando como base os parâmetros curriculares e as orientações da Secreatira Municipal de Educação do Município (SEMED). Desse modo o plano de ensino é construído em vista de modo abrangente a despertar as competências do aluno, utilizando os PCN`s e as matrizes de conteúdos formulada pelos professores do município.

QUADRO 1: Plano de ensino da disciplina Matemática $6^{\circ}$ ano

\section{PLANEJAMENTO QUINZENAL}

\section{Habilidades}

$>$ Reconhecer que a forma decimal de um número racional pode ser finita ou infinita periódica.

$>$ Reconhecer que o número racional na forma fracionária corresponde a um decimal infinito e periódico.

$>$ Representar uma dízima periódica e forma de fração.

$>$ Localizar os números reais na reta numérica.

\section{Objetivos}

$>$ Estabelecer relações, interpretar e utilizar os diferentes conjuntos numéricos em contextos matemáticos, sociais e de outras áreas de conhecimento.

$>$ Identificar e utilizar valores aproximados para números racionais de maneira adequada ao contexto do problema ou da situação em estudo. 


\begin{tabular}{|c|c|c|}
\hline \multirow[b]{2}{*}{ 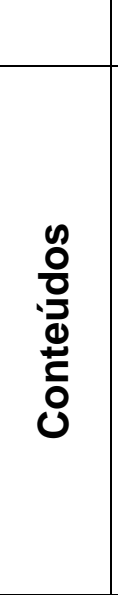 } & $1^{\text {a }}$ Semana & $2^{a}$ Semana \\
\hline & $\begin{array}{l}\text { - Oração e acolhida: texto uma diálogo } \\
\text { com o aluno; } \\
\text { - Raiz quadrada (exata e inexata); } \\
\text { - } \quad \text { Exercícios de fixação; } \\
\text { - Conjuntos Numéricos; } \\
\text { - Exercícios de contagem, código e } \\
\text { ordenação, usando o mapa político do } \\
\text { Brasil; } \\
\text { - Conjunto dos números racionais; } \\
\text { - Trabalhando com os números } \\
\text { racionais no cotidiano dos alunos: cálculo do } \\
\text { IMC. }\end{array}$ & $\begin{array}{l}\text { - Números racionais e as dizimas } \\
\text { periódicas; } \\
\text { - } \quad \text { Exercícios de fixação; } \\
\text { - } \quad \text { Conjunto dos números irracionais; } \\
\text { - Atividades com os números racionais } \\
\text { notáveis; } \\
\text { - Pesquisa e explanação sobre o } \pi \text { e o } \varphi \text {; } \\
\text { - } \quad \text { Conjunto dos números reais; } \\
\text { - Os números reais na reta numerada; } \\
\text { - Números reais e suas propriedades. }\end{array}$ \\
\hline \multirow[b]{2}{*}{ 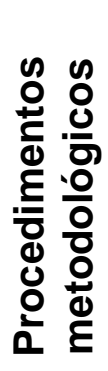 } & $1^{a}$ Semana & $2^{a}$ Semana \\
\hline & $\begin{array}{l}\text { - Aulas expositivas e dialogada; } \\
\text { - Complementação com o livro. }\end{array}$ & $\begin{array}{l}\text { - Aula expositiva e dialogada; } \\
\text { - Complementação com o livro. }\end{array}$ \\
\hline \multirow{2}{*}{ 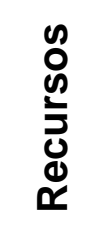 } & $1^{a}$ Semana & $2^{a}$ Semana \\
\hline & $\begin{array}{l}\square \text { Quadro branco, pinceis, livro didático e } \\
\text { internet. }\end{array}$ & $\begin{array}{l}\square \text { Quadro branco, pinceis, livro didático e } \\
\text { internet. }\end{array}$ \\
\hline \multirow{2}{*}{ 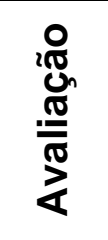 } & $1^{a}$ Semana & $2^{a}$ Semana \\
\hline & $\begin{array}{l}\text { Participação, interesse no decorrer das } \\
\text { aulas, avaliar os exercícios resolvidos em } \\
\text { sala, para assim perceber as dificuldades } \\
\text { encontradas pelos alunos. }\end{array}$ & $\begin{array}{l}\text { Participação, interesse no decorrer das } \\
\text { aulas, avaliar os exercícios resolvidos em } \\
\text { sala, para assim perceber as dificuldades } \\
\text { encontradas pelos alunos. }\end{array}$ \\
\hline
\end{tabular}

Fonte: Arquivo da Escola de Ensino Fundamental Sebastião de Oliveira (2018).

A proposta de atividade desenvolvida no plano de ensino exemplificado no QUADRO 1, pode-se demonstrar como o professor, a partir do que está orientado nos PCNs e reafirmado pela SEMED, se dedica para cumprir as atividades educacionais em vista de despertar as competências e habilidades dos alunos visando melhoria no processo de ensino e uma aprendizagem significativa.

Embora os documentos da proposta da BNCC também trilhem nessa direção, por falta de exemplos de sua aplicação ainda não podemos dizer especificamente se ela se realiza efetivamente como já é feita com os PCNs, 
por isso cogitamos a partir do que está tramitando nas esferas do sistema de ensino e o que estamos tratando na escola em preparação à essa mudança.

Com a submissão da proposta da BNCC, e que deverá ser implementada nos próximos anos em todas as escolas da rede pública e privada do Brasil, não temos clara noção do impacto de sua efetivação no ensino. Entretanto, o que sabemos é que esse será um processo que exigirá empenho de toda a comunidade escolar, e para que ocorra alinhamento nas discussões é preciso que todos os que estão envolvidos no cotidiano escolar estejam apropriados do seu conteúdo.

Para contribuir com os debates e dar apoio aos gestores o Ministério da Educação (MEC) em parceria com o Conselho Nacional de Secretários de Educação (Consed) e a União Nacional de Dirigentes Municipais de Educação (Undime), elaboraram materiais de estudo para auxiliar os debates no âmbito escolar. Desse modo, afim de acompanhar e se envolver no processo de implantação da BNCC a Escola Sebastião de Oliveira se organizou no ano de 2017 sessões de estudo onde foram realizadas leituras dos documentos inerentes a Base Curricular, levantamentos de discussões, composição de críticas e apontamentos de sugestões para o trabalho educacional. Com o movimento da mobilização nacional sobre a BNCC em 2018, mais uma vez a escola promoveu outra sessão de discussões denominada o "Dia D da Base".

A programação do Dia D da BNCC ocorria no dia 06 de março de 2018, na escola Municipal de Ensino Fundamental Sebastiao de Oliveira, foi um evento organizado pela SEMED em conjunto com a gestão da escola. No início da programação foi feito um apanhado geral das discussões sobre a temática, em seguida foi tratado sobre definição de competência, marcos legais que embasam a BNCC, organização estrutura do documento e suas atribuições gerais. Em um outro momento, os participantes foram conduzidos para discussões de grupos sobre cada área de conhecimento.

Em específico sobre estudo da BNCC na área da Matemática os professores foram organizados em grupos, para analisar as competências, habilidades e mudanças propostas pelo documento, analisando de acordo com 
as experiências vividas e complementando o texto com clareza adicionando aspectos que não foram contempladas, observando se as propostas estão adequadas ao ano de escolaridade.

Dentre as proposições, uma questão que chamou a atenção foi a preocupação dos professores em saber se depois de aprovada a BNCC os professores vão ter autonomia para participar do processo de implementação e discussão do currículo escolar de maneira efetiva, ou só irão receber o currículo pronto, pois sabemos que o mesmo não é imparcial.

É preciso se atentar para o fato de que o currículo não é neutro; ao ser veículo de conhecimentos selecionados, ele se liga ao poder, à homogeneização ou diferenciação da escola e por isso os educadores precisam estar alertas às suas implicações sociológicas e culturais quando de sua estruturação. (OLIVEIRA, 2008, p. 545)

Da forma como tem se dado o trabalho de implementação da BNCC, em que falta de diálogo com a comunidade escolar tem gerado muitas dúvidas e incertezas sobre a democratização de sua realização, pois, pelo percebido as formulações e definições sobre o documento tem ficado mais para as organizações representativas das esferas representativas das administrações públicas, enquanto que as escolas não foram consultadas de forma real.

Por essa limitação na participação do processo de construção do documento o que podemos inferir é que um dos maiores desafios na efetivação do currículo comum será a aplicação por parte dos educadores, visto que, além das condições precárias na infraestrutura na maioria das escolas públicas, também imperará a falta de conhecimento sobre o currículo devido à falta de transparência no processo de democratização da nova proposta.

Pelo tempo em que a proposta está tramitando em processo de implementação, entendemos que a BNCC já se configura como realidade, no entanto é necessário que ofereça condições principalmente aos professores que são os principais agentes desse processo, investimentos em formações 
continuadas durante e após a implementação, melhores condições de trabalho, e valorização profissional dos agentes educacionais.

Pelo que podemos notar somente as escolas que foram mobilizadas e em parceria com a SEMED para fazer alguma discussão sobre o tema estão conseguindo acompanhar a Base e saber os procedimentos para atender as competências requieridas pelo documento. No mais, sem uma política de formação curricular sobre BNCC se torna difícil acompanhar uma proposta que visa garantir ao aprendizado de conhecimentos e habilidades comuns, posto, no momento que seja exigido dos professsores a construção dos planos de aula, eles não corresponderão as orientações do documento base, devido não estarem articulados na concepção de Libâneo, (1994, p. 22) quando diz que: "o planejamento tem grande importância por tratar-se de: Um processo de racionalização, organização e coordenação da ação docente, articulando a atividade escolar e a problemática do contexto social".

Quanto a organização do plano de ensino da disciplina de Matemática na escola Sebastião de Oliveira, como nas demais escolas municipais são orientadas por uma matriz de competências, habilidades e conteúdos elaborada pelos professores no ano de 2017, para alinhar o ensino da rede básica em Altamira com o intuito de melhorar processo de ensino e aprendizagem, conforme destacado no artigo 194 da Lei Orgânica do município.

I- elaborar diretrizes para a política educacional;

II- criar mecanismos que favoreçam acesso e permanência nas escolas para qualquer pessoa, independentemente de cor, raça, religião etc;

III- garantir ensino público e gratuito a todas as crianças e adolescentes em situação de risco que estejam fora do sistema regular do ensino ou em defasagem de idade/série. (ALTAMIRA, 2017, p. 72)

De tudo que foi tratado e pelo que averiguamos a formulação da matriz 
de ensino tem tudo para ser benéfica, pois, ainda é comum percebermos a desigualdade de conteúdo, posto alunos que mudavam de escola e se deparavam com assuntos já vistos ou totalmente diferentes, isso fazia com que os mesmos fossem prejudicados. Entretanto, já em relação a BNCC como educadora tenho minhas dúvidas, pois, se igualar o currículo alcançará o sucesso desejado por todos nós, visto que as diferenças em nosso país são grandes, culturais e socioeconômicas. E de outra forma, precisaremos de um tempo consideravelmente grande para aprender a efetivar o que está nessa proposta.

\section{Conclusão}

O ensino da Matemática sempre foi desafio, são vários fatores que contribuem para que a prática se torne menos eficaz. Falta de tempo para desenvolver um trabalho pleno, superlotação nas salas, falta de interesse dos alunos, má remuneração dos professores. Destarte, o processo de ensino e aprendizagem da Matemática, e a necessidade de mudanças concretas para que possa existir uma aprendizagem significativa, será necessário buscar novos recursos para que os alunos possam entender a importância dos conceitos e sua aplicabilidade no seu cotidiano.

Diante da realidade, com a experiência obtida durante as discussões sobre a BNCC em uma escola do município de Altamira-Pa, foi possível constatar que o processo de implantação causa dúvidas e inquietações, a preocupação dos professores perpassam a elaboração de um novo currículo, teremos condições necessárias, tanto pedagógicas quanto estruturais, existirá espaços para as particularidades de cada instituição de ensino.

Uma das formas encontradas para diminuir o impacto das transformações anunciadas pelo processo de implantação da BNCC no conxto das escolas do município, foi a realização de um trabalho de articulação entre SEMED e a comunidade escolar, que durante o processo de tramitação do documento base, procurou promover encontros e com isso começar a fazer os 
esclarecimentos necessários ao público. Do resultado desse trabalho, na SEMED foi criada uma coordenação para trabalhar exclusivamente junto das escolas para facilitar o processo de transição para a configuração de currículo comum.

Sabemos a importância de uma base comum, mas não podemos deixar de discutir a autonomia que a escola deverá ter, ressaltando que a escola não deverá abandonar seu projeto político-pedagógico, pois ele traz os anseios e identidade da instituição.

Diante do exposto, constatamos que há a necessidade de mais formações e articulações com sobre o processo de implantação da BNCC com a comunidade escolar de cada instituição de ensino do pais, também que sejam acionadas as entidades representativas da sociedade civil junto com as universidades para que o processo de consolidação da base comum seja democrático e participativo.

\section{Referências}

ALTAMIRA. Prefeitura Municipal de Altamira. Lei Orgânica do Município de Altamira. s.e.: Altamira, 2017

BRASIL, Lei de Diretrizes e Base da Educação Nacional: lei 9.394,20 de dezembro de 1996, que estabelece as diretrizes e bases da educação nacional [recurso eletrônico]. $7^{\mathrm{a}} \quad$ Ed. Brasília: Câmara dos Deputados, 2012. Disponível em: $<$ http://bd.camara.gov.br> Acesso em 20 de Outubro de 2018.

BRASIL. Ministério da Educação. Base Nacional Comum Curricular - Documento preliminar. MEC: Brasília, DF, 2017

BRASIL. Ministério da Educação. Secretaria de Educação Fundamental. Parâmetros Curriculares Nacionais: Matemática. MEC: Brasília, 1998.

D' AMBRÓMSIO, U. Matemática, ensino e educação: uma proposta global. São Paulo: Temas \& Debates, 1991

ESCOLA, S. de O. Plano de Ensino de Matemática $6^{\circ}$ ano. s.e.: Altamira, 2018

FERREIRA, A. C. Desafio de ensinar-aprender matemática no curso noturno: Um estudo das crenças de estudantes de uma escola pública de Belo Horizonte. Dissertação de mestrado em Educação. Campinas: Universidade Estadual de Campinas - UNICAMP, 1998. Disponível em: Disponível em: $<$ http://www.repositorio.unicamp.br/handle/REPOSIP/252523>. Acesso em: 23 jul. 
2018.

FREIRE, P. Pedagogia do Oprimido. Rio de Janeiro: Paz e Terra, 2005.

LIBÂNEO, J. C. Didática. 21 ed. SP: Cortez,1994.

MARCONI, M. de A. LAKATOS, E. M. Fundamentos de Metodologia Científica. $8^{\text {a }}$ ed.-[2. Reimpr.] São Paulo: Atlas, 2017

MARCONI, M. de A. LAKATOS, E. M. Metodologia Científica. $5^{a}$ ed. São Paulo: Atlas, 2011.

OLIVEIRA, Z. M. F. Currículo: um instrumento educacional, social e cultural. Rev. Diálogo Educ., Curitiba, v. 8, n. 24, p. 535-548, maio/ago. 2008.

PINTO, A. H. A Base Nacional Comum Curricular e o Ensino de Matemática: flexibilização ou engessamento do currículo escolar. Bolema (Rio Claro), v. 31, p. 1045-1060, 2017. Disponível em: http://www.scielo.br/pdf/bolema/v31n59/0103636X-bolema-31-59-1045.pdf. Acesso em: 08/11/2018

RABELO, E. E. Ausubel - Significação ou Mecanização? Cadernos Ensinar nº 03CP/UFMG-CECIMIG. Belo Horizonte, 2000. Disponível em: http//:www.rabelo.pro.br/artigos/Ausubel.html. Acesso em: 25 de Outubro de 2018

VITTI, C. M. Matemática com prazer, a partir da história e da geometria. $2^{\mathrm{a}}$ Ed. Piracicaba - São Paulo. Editora UNIMEP. 1999.

Recebido em dezembro de 2019.

Aprovado em março de 2020. 